\title{
Weight management barriers and facilitators after breast cancer in Australian women: a national survey
}

\author{
Carolyn Ee ${ }^{1 *}$ D, Adele Elizabeth Cave ${ }^{1}$, Dhevaksha Naidoo ${ }^{1}$, Kellie Bilinski ${ }^{1}$ and John Boyages ${ }^{2}$
}

\begin{abstract}
Background: Breast cancer is the most common cancer in women worldwide. Weight gain after breast cancer is associated with poorer health outcomes. The aim of this study was to describe how Australian breast cancer survivors are currently managing their weight.

Methods: Online cross-sectional survey open to any woman living in Australia who self-identified as having breast cancer, between November 2017 and January 2018.

Results: We received 309 responses. Most respondents described their diet as good/excellent and reported moderate-high levels of weight self-efficacy. Despite this, the proportion of overweight/obesity increased from 47\% at time of diagnosis to $67 \%$ at time of survey. More than three quarters of respondents did not receive any advice on weight gain prevention at the time of diagnosis. 39\% of women reported being less active after cancer diagnosis, and and few weight loss interventions were perceived to be effective. Facilitators were structured exercise programs, prescribed diets, and accountability to someone else, while commonly cited barriers were lack of motivation/willpower, fatigue, and difficulty maintaining weight. Women who cited fatigue as a barrier were almost twice as likely to be doing low levels of physical activity (PA) or no PA than women who did not cite fatigue as a barrier.

Conclusions: We report high levels of concern about weight gain after $B C$ and significant gaps in service provision around weight gain prevention and weight management. Women with BC should be provided with support for weight gain prevention in the early survivorship phase, which should include structured PA and dietary changes in combination with behavioural change and social support. Weight gain prevention or weight loss programs should address barriers such as fatigue. More research is required on the effectiveness of diet and exercise interventions in BC survivors, particularly with regard to weight gain prevention.
\end{abstract}

Keywords: Breast cancer, DCIS, Obesity, Weight gain, Barriers and facilitators, Lifestyle

\section{Background}

Globally, breast cancer is the most common cancer in women [1-3]. There were over 2 million new diagnoses of breast cancer (BC) worldwide in 2018, with this figure expected to rise to 3 million by 2040 [2]. Obesity is a known

\footnotetext{
* Correspondence: c.ee@westernsydney.edu.au

'NICM Health Research Institute, Western Sydney University, Locked Bag 1797, Penrith, NSW, Australia

Full list of author information is available at the end of the article
}

risk factor for $\mathrm{BC}[4]$ and may lead to poorer outcomes for BC survivors. A meta-analysis of 82 studies reported a $41 \%$ relative increase in all-cause mortality for breast cancer survivors with obesity compared with women of normal weight, with a higher risk in premenopausal women [5].

Additionally, weight gain after breast cancer is common [3] and may increase the risk of disease recurrence and mortality. A meta-analysis of eight studies, including observational studies and randomised controlled trials,

(c) The Author(s). 2020 Open Access This article is licensed under a Creative Commons Attribution 4.0 International License, which permits use, sharing, adaptation, distribution and reproduction in any medium or format, as long as you give appropriate credit to the original author(s) and the source, provide a link to the Creative Commons licence, and indicate if changes were made. The images or other third party material in this article are included in the article's Creative Commons licence, unless indicated otherwise in a credit line to the material. If material is not included in the article's Creative Commons licence and your intended use is not permitted by statutory regulation or exceeds the permitted use, you will need to obtain permission directly from the copyright holder. To view a copy of this licence, visit http://creativecommons.org/licenses/by/4.0/ The Creative Commons Public Domain Dedication waiver (http://creativecommons.org/publicdomain/zero/1.0/) applies to the data made available in this article, unless otherwise stated in a credit line to the data. 
reported that weight gain of greater than $10 \%$ of baseline body weight was associated with a hazard ratio of 1.23 for all-cause mortality compared with weight maintenance, and may be associated with an increase in $\mathrm{BC}$ recurrence [6]. Weight gain after breast cancer diagnosis is thought to be multifactorial and related to the use of systemic treatment as well as changes in lifestyle [3]. Given the growing population of breast cancer survivors, increased survival due to advances in treatment [7] and the link between weight gain and adverse health outcomes, research into weight after breast cancer is of critical importance.

It is anticipated that there will be 25,000 new cases of BC diagnosed annually in Australia by 2040 [1]. Yet, there is a relative paucity of research addressing the needs of women who experience weight gain in Australia. One prospective cohort study described the changes in weight gain in women diagnosed with early breast cancer in the state of Queensland [8], however there has not been any national population-based data until the publication of our national survey in 2020 [9]. Moreover, there is a lack of research about barriers and facilitators of weight management after breast cancer in Australia. A qualitative study of 14 women with $\mathrm{BC}$ who had been randomized to a 12-month weight loss intervention explored women's experiences of making weight, dietary and physical activity (PA) changes during the trial [10], however little is known about barriers and facilitators of weight management in real-world conditions as opposed to weight management within the context of a clinical trial.

The aim of this study was to describe the management of weight amongst respondents to a cross-sectional Australian survey and explore barriers and facilitators of successful weight management in this population.

\section{Methods}

\section{Study design and inclusion criteria}

Our methods have been previously described [9]. We conducted an anonymous self-administered online crosssectional survey from November 2017 until January 2018 using the survey platform Qualtrics [11]. Women who -self-identified as having breast cancer and who were living in Australia were invited to complete the survey. Women were recruited from the Breast Cancer Network Australia (BCNA) Review and Survey Group, who have agreed to receive emails about research studies. BCNA is the largest breast cancer advocacy group in Australia. BCNA have decided to limit research requests to this select group, therefore allowing researchers to access women who are engaged in the research process, while protecting the rest of BCNA from frequent research requests. The survey was emailed on December 5th, 2017 and a reminder email was sent to 1835 members on January 15th, 2018 (Additional file 1). We also recruited women from online communities (women's health organization social media pages, online breast cancer support groups in Australia) and through word of mouth.

\section{Survey instrument}

Two clinicians (CE, a general practitioner/family physician and JB, a radiation oncologist) developed the survey after reviewing previous literature on weight after $\mathrm{BC}$ and incorporated feedback from six BCNA representatives and several health researchers. The 60 -item survey included questions on the characteristics, medical details such as diagnosis and treatment, lifestyle habits, and weight and weight management of women. Ethics approval for this study was provided by the Human Research Ethics Committee, Western Sydney University (H12444, Oct 2017). Additional file 1 contains details of the specific demographic, medical, menopausal and lymphoedema data that were collected in the survey. In this manuscript we report on how women were managing their weight, and the perceived barriers and facilitators to successful weight management.

\section{Weight after diagnosis}

Weight was self-reported by the survey respondents, who were asked about their current weight $(\mathrm{kg})$ and height $(\mathrm{m})$ at time of diagnosis. Body Mass Index was calculated from these measures as weight $/$ height $^{2}$. A Pearsons correlation was performed to test the relationship between weight gain and time since diagnosis. Women were asked about the pattern of weight since diagnosis with options for "gained weight overall", "lost weight overall", "weight stable" or "weight has fluctuated a great deal". We used an 11-point Likert scale to assess concern about weight from 0 (not at all concerned) to 10 (very concerned). Experiences with a range of weight loss interventions and the perceived effectiveness of the interventions on was described using a five-point Likert scale from 1 (not at all effective) to 5 (very effective). The responses were further dichotomized into 1 to 2 (not effective) and 3 to 5 (effective). Women were also asked about perceived barriers and facilitators to successful weight loss and weight maintenance, and what they believed should be research priorities in this area.

\section{Lifestyle habits}

Women were asked about any specific diets followed, intake of recommended daily serves of fruit and vegetables, advice received as to restricting diet, self-assessed diet quality on a five-point Likert scale from 1 (poor) to 5 (excellent), cigarette use, alcohol use, self-assessed PA level, and self-assessed health status. The validated Weight Self Efficacy Scale (WEL-SF) [12] was used to evaluate how confident women now felt about being able to successfully resist the desire to overeat in eight 
different situations on an 11-point Likert scale from 0 (not confident at all) to 10 (very confident). We further dichotomised the responses into "Not confident" (0-4) and "Confident" (5-10). PA levels were calculated according to the number of 20-min sessions of less vigorous exercise or more vigorous exercise a week, given a weighting and described in terms of MET (metabolic cost) minutes where MET minutes less than 80 were coded as no PA, 80 to 400 as low, 400 to 560 as moderate and more than 560 as high. A value of 4 METs was given to moderate PA and 7.5 to vigorous PA [13].

\section{Statistical analysis}

Stata Corp 13.1 [14] was used to analyse the data presented in this report and the data analysis used descriptive statistics, as well as odds ratio analyses to explore associations between medical symptoms, cited barriers, and lifestyle habits.

\section{Results}

\section{Survey response}

The response rate from the BCNA Review and Survey group was $15 \%$ (283/1857). A further 26 women responded to the survey from other channels giving a total of 309 responses, of which 273 completed the survey ( $95.8 \%$ completion rate).

\section{Sample characteristics}

Our sample has been previously described [9]. Table 1 describes the demographic characteristics of respondents. The majority of women were Caucasian $(92.5 \%, n=285)$ with a mean age of 59.1 years $(S D=9.5$, range $33-78, n=$ 298). Characteristics were similar across BCNA members and non-BCNA respondents except that there was a higher proportion of women in the non-BCNA group who were self-employed ( $23 \%$ vs $10 \%$ ) and in the BCNA group who were retired (33\% vs $23 \%$ ), although there were no differences between these groups on Pearson's Chisquared test, $X^{2}(7, N=308)=6.9912, p=0.430$. The majority of women $(83 \%)$ had been diagnosed with Stage 0III breast cancer. The mean time since diagnosis of breast cancer was 8.22 years $(S . D=5.14$, range $=1-32$ years $)$. Most women were either premenopausal $(43 \%)$ or perimenopausal (12\%) at the time of diagnosis.

\section{Weight gain}

Weight at diagnosis was reported by $90 \%$ of respondents (278 women) and current weight was reported by $95 \%$ of respondents (293 women). The proportion of women who were overweight or obese (BMI $\geq 25)$ increased from $48 \%$ at the time of diagnosis, to $67 \%$ at the time of completing the survey. In particular, the proportion of women who were obese almost doubled, from 17 to $32 \%$. Mean current and pre-cancer self-reported weight
Table 1 Demographic characteristics of survey respondents

\begin{tabular}{|c|c|c|}
\hline Description & $\mathrm{N}$ (responses) & Percentage \\
\hline \multicolumn{3}{|l|}{ State $(n=309)$} \\
\hline Australian Capital Territory & 14 & 4.5 \\
\hline New South Wales & 91 & 29.5 \\
\hline Northern Territory & 0 & 0.0 \\
\hline Queensland & 48 & 15.5 \\
\hline South Australia & 28 & 9.1 \\
\hline Tasmania & 3 & 1.0 \\
\hline Victoria & 95 & 30.7 \\
\hline Western Australia & 30 & 9.7 \\
\hline \multicolumn{3}{|l|}{ Education $(n=307)$} \\
\hline High school- year 10 & 30 & 9.8 \\
\hline High school- year 12 & 35 & 11.4 \\
\hline Vocational College & 55 & 17.9 \\
\hline Bachelor's degree & 90 & 29.3 \\
\hline Postgraduate degree & 97 & 31.6 \\
\hline \multicolumn{3}{|l|}{ Ethnicity $(n=308)$} \\
\hline European/Anglo Saxon/Caucasian & 285 & 92.5 \\
\hline Asian & 5 & 1.6 \\
\hline $\begin{array}{l}\text { Oceanic (incl. Australian and } \\
\text { New Zealand first peoples, } \\
\text { Polynesian and Micronesian) }\end{array}$ & 13 & 4.2 \\
\hline North/South/Central American & 2 & 0.7 \\
\hline Mixed ethnicity & 2 & 0.7 \\
\hline Indian & 1 & 0.3 \\
\hline \multicolumn{3}{|l|}{ Employment $(n=308)$} \\
\hline Employee & 140 & 45.5 \\
\hline Self-employed & 33 & 10.7 \\
\hline $\begin{array}{l}\text { Home duties/caring for children } \\
\text { or family }\end{array}$ & 15 & 4.9 \\
\hline $\begin{array}{l}\text { In education (going to school, } \\
\text { university, etc.) }\end{array}$ & 4 & 1.3 \\
\hline Doing voluntary work & 10 & 3.3 \\
\hline Unable to work because of illness & 6 & 2.0 \\
\hline Unable to work for other reasons & 1 & 0.3 \\
\hline Retired & 99 & 32.1 \\
\hline \multicolumn{3}{|l|}{ Relationship Status ( $n=309$ ) } \\
\hline Single & 39 & 12.6 \\
\hline Married/De Facto (living with partner) & 230 & 74.4 \\
\hline $\begin{array}{l}\text { In a relationship but not living } \\
\text { with partner }\end{array}$ & 7 & 2.3 \\
\hline Divorced/separated & 24 & 7.8 \\
\hline Widowed & 9 & 2.9 \\
\hline
\end{tabular}

of survey respondents was $76.08 \mathrm{~kg}(S D=15.49$, range, $46-150 \mathrm{~kg}$ ) and $71.24 \mathrm{~kg}$ (SD 14.01, range 47-158) respectively. Mean self-reported current BMI was 28.02 $(S D=5.88, n=285)$ and mean pre-cancer BMI was 26.37 
$(S D=5.92, n=271)$. One fifth $(21.03 \%)$ of women went from being in the healthy weight range at diagnosis $(\mathrm{BMI}<25)$, to an unhealthy weight range $(\mathrm{BMI}>25)$, and $60.52 \%$ of women reported an increase of BMI of greater than $1 \mathrm{~kg} / \mathrm{m}^{2}$.

Most women (64\%) reported having gained weight overall after diagnosis, with an average weight gain of $9.07 \mathrm{~kg}$ in this group. Of the women who reported gaining weight overall, $77.14 \%$ of women gained $\geq 5 \mathrm{~kg}$ of weight. Weight gain was not correlated with time since diagnosis $(n=173, r=.114, p=0.07)$. More than half $(52.85 \%, n=148 / 280)$ of women rated their concern about weight as high (8-10).

\section{Other medical conditions and symptoms}

Table 2 describes the current medical conditions and symptoms that were being experienced by the respondents. The majority $(62.19 \%, n=125 / 201)$ of women reported they were currently using hormonal therapy, of which $40 \%$ were using tamoxifen, and $44 \%$ were using an aromatase inhibitor.

\section{Lifestyle habits}

Table 2 details the lifestyle habits of respondents. About $40 \%$ of women had tried some kind of diet in the previous 12 months, with the most popular diets being a "healthy balanced" diet (25/124), the 5:2 diet (26/124), vegetarian (17/124), Weight Watchers (17/124), the Dukan and Atkins diets (11 and 7/124 respectively), and meal replacements (5/124). In all, 23 different kinds of diets had been tried. The majority (58.6\%) of women reported eating the recommended serves of fruit and vegetables, and $88.8 \%$ of women described their diet as excellent $(n=24)$, very good $(n=126)$ or good $(n=118)$. The majority of women $(83.6 \%)$ rated their health as good and above, although $38.4 \%$ of women reported that they were less active than they were at the time of cancer diagnosis and $41.6 \%$ did no exercise or low levels of PA. About a quarter of women had been told to restrict their diet. Of these women, 10/55 reported being told to stop eating dairy, whilst eliminating red meat $(9 \%, n=5)$ and reducing volume/portion size $(9 \%, n=5)$ was also commonly given advice, mostly by an oncologist or a nurse.

The total number of respondents varied across the WELSF questions from 275 to 280 . The majority of women rated themselves as moderately to very confident across all questions although they were slightly less likely to rate themselves as confident ( $0-4)$ for the questions on resisting eating when depressed and down $(40.5 \%, n=113)$, and when in a social setting $(36 \%, n=99)$ (see Fig. 1).

\section{Advice about weight loss or weight gain}

More than three quarters $(79.79 \%, n=233 / 292)$ of women reported not receiving any advice about weight
Table 2 Medical and lifestyle characteristics of survey respondents

\begin{tabular}{|c|c|c|}
\hline Description & $\mathrm{N}$ & $\%$ \\
\hline \multicolumn{3}{|l|}{ Medical conditions and symptoms $(n=228)$} \\
\hline Diabetes not requiring insulin & 11 & 4.8 \\
\hline $\begin{array}{l}\text { Impaired glucose tolerance (abnormal glucose } \\
\text { tolerance test) }\end{array}$ & 10 & 4.4 \\
\hline $\begin{array}{l}\text { Fasting hyperglycemia (high blood sugar levels } \\
\text { but no diabetes) }\end{array}$ & 5 & 2.2 \\
\hline High cholesterol & 79 & 34.7 \\
\hline High blood pressure & 78 & 34.2 \\
\hline Neuropathy & 64 & 28.1 \\
\hline Hot flushes & 152 & 66.7 \\
\hline \multicolumn{3}{|l|}{ Self-Rated Diet $(n=302)$} \\
\hline Excellent & 24 & 7.95 \\
\hline Very good & 126 & 41.72 \\
\hline Good & 118 & 39.07 \\
\hline Fair & 29 & 9.60 \\
\hline Poor & 5 & 1.66 \\
\hline \multicolumn{3}{|l|}{ Smoking Status $(n=302)$} \\
\hline Never Smoked & 192 & 63.58 \\
\hline Ex-Smoker & 101 & 33.44 \\
\hline Recently Quit, Ex-smoker in the last 3 months & 3 & 0.99 \\
\hline Current Smoker & 6 & 1.99 \\
\hline \multicolumn{3}{|l|}{ Alcohol $(n=292)$} \\
\hline Non-drinker & 76 & 26.03 \\
\hline 1-7 standard drinks a week & 171 & 58.56 \\
\hline 8-14 standard drinks a week & 40 & 13.70 \\
\hline$>14$ standard drinks a week & 5 & 1.71 \\
\hline \multicolumn{3}{|l|}{ Physical activity level (MET) $(n=305)$} \\
\hline None $(<80)$ & 17 & 5.57 \\
\hline Low $(80-<400)$ & 110 & 36.07 \\
\hline Moderate $(400-<560)$ & 65 & 21.31 \\
\hline $\operatorname{High}(>=560)$ & 113 & 37.05 \\
\hline \multicolumn{3}{|l|}{ Current Physical Activity (c.f before diagnosis) $(n=294)$} \\
\hline I'm more active & 70 & 23.81 \\
\hline I'm less active & 113 & 38.43 \\
\hline I'm as active as I was & 111 & 37.76 \\
\hline \multicolumn{3}{|l|}{ Self-Rated Health $(n=292)$} \\
\hline Excellent & 23 & 7.88 \\
\hline Very good & 100 & 34.25 \\
\hline Good & 121 & 41.44 \\
\hline Fair & 45 & 15.41 \\
\hline Poor & 3 & 1.02 \\
\hline
\end{tabular}

MET metabolic cost (per week) in minutes

loss or weight gain prevention at the time of diagnosis. If advice was given, it was provided mostly by an oncologist $(46 \%, n=26 / 56)$ or a $\mathrm{BC}$ nurse $(12.5 \%, n=7 / 56)$. 


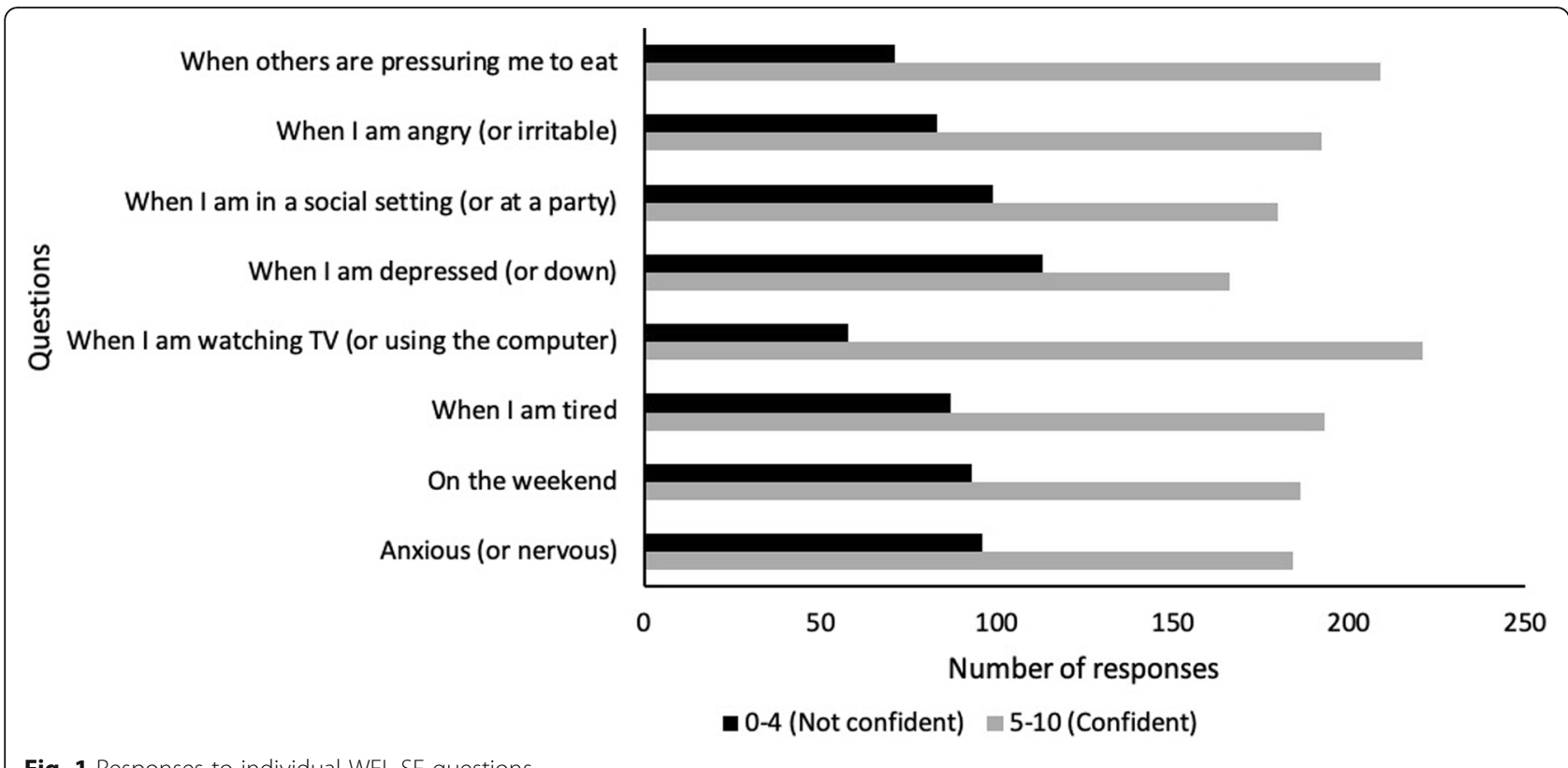

Fig. 1 Responses to individual WEL-SF questions

\section{Treatments for weight loss}

Figure 2 details the number of responses for each of the treatments in terms of their perceived effectiveness for weight loss. Overall, there were few weight loss treatments that women felt were moderately to extremely effective (3-5) including exercise $(n=131)$ and diet $(n=108)$.

\section{Barriers to weight loss}

Figure 3 describes the perceived barriers to weight loss in this cohort of women $(n=256)$.

Women who reported experiencing hot flushes were 2.53 times more likely to report fatigue as a barrier (95\% CI 1.53-4.19, $p=0.0001$ ) while the relationship between peripheral neuropathy or lymphoedema and fatigue was not significant. The relationship between willpower and fatigue as cited barriers approached statistical significance (OR 1.58, 95\% CI .96-2.60, $p=0.0547$ ).

Women who cited fatigue as a barrier were almost twice as likely to be doing low levels of PA or no PA than women who did not cite fatigue as a barrier (OR $1.86,95 \%$ CI $1.123 .08, p=0.0107)$. However, there was no association between experiencing hot flushes and doing low or no levels of PA.

\section{Facilitators of weight loss}

Figure 4 describes the perceived facilitators of weight loss in this cohort of women $(n=233)$. The most commonly described facilitators were a structured exercise program $(46.4 \%, n=108)$, prescribed diet $(36.5 \%, n=85)$, accountability to someone else $(24.0 \%, n=56)$ and social support $(17.6 \%, n=41)$. Only $4.3 \%(n=10)$ of women thought a breast cancer specific program would be helpful.

\section{Research priorities}

Among 273 respondents to the question on research priorities, the following were prioritised: PA (68.1\%, $n=$ $186)$, weight maintenance $(56.0 \%, n=153)$, diet $(53.1 \%$, $n=145)$, and social support programs $(39.6 \%, n=108)$. Few women wanted more research on surgical treatments $(5.86 \%, n=16)$, psychological strategies $(5.13 \%$, $n=14)$ or individualised programs $(1.1 \%, n=3)$.

\section{Discussion}

In this survey of Australian women with breast cancer, we report an increase in the proportion of overweight and obese women from time of diagnosis to post diagnosis, high levels of concern about weight gain, and significant gaps in service provision around weight management and weight gain prevention.

Less than one quarter of women reported receiving advice about weight loss or weight gain prevention at the time of diagnosis. Findings from surveys of oncologists in Canada and the UK are consistent with this data, showing that less than half discuss PA and weight management with their cancer patients $[15,16]$. Further, at the time of $\mathrm{BC}$ diagnosis women may be more motivated and receptive to lifestyle change [17] suggesting a missed opportunity for health professionals to provide reliable recommendations for lifestyle and weight management to $\mathrm{BC}$ patients. Advice on the importance of weight gain 


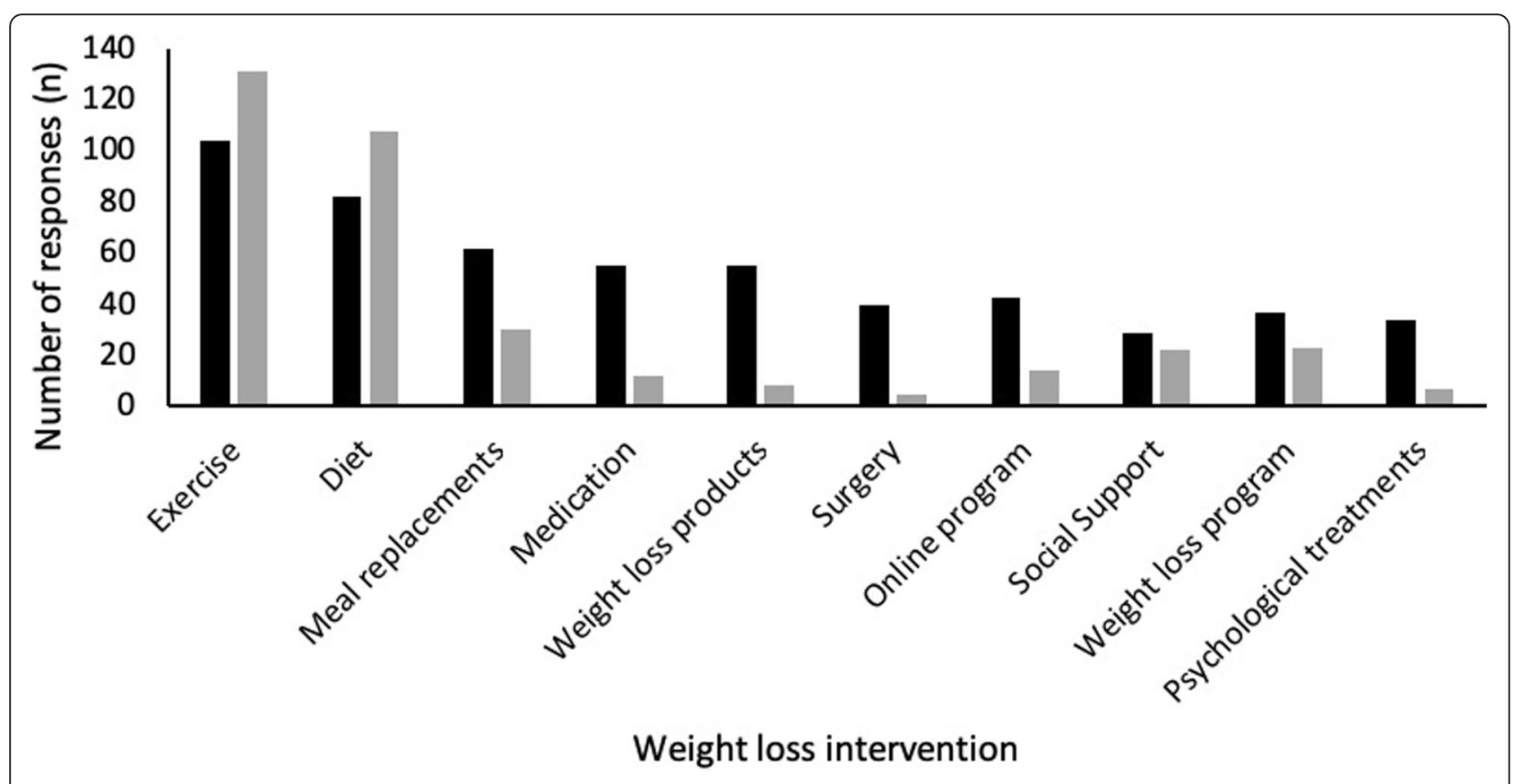

- Not Effective $\quad$ Effective

Fig. 2 Perceived effectiveness of weight loss interventions

prevention should be incorporated into standard breast cancer management advice in order to optimize outcomes for BC survivors. Additionally, the most commonly visited health care providers were reportedly breast surgeons, physiotherapists and medical oncologists. These health professionals could play a vital role in monitoring weight, providing advice on weight gain prevention and referring to a multidisciplinary team. In particular, exercise physiologists and dieticians can play an important role in tailoring diet and exercise interventions for the individual woman.

Although the majority of women described their diet as excellent, very good or good, with $57 \%$ reportedly consuming the recommended daily intake of fruits and vegetables, and most women reporting moderate to high levels of weight self-efficacy, women reported generally high levels of concern about their weight. Of concern, $15 \%$ of women were drinking more than the recommended intake of one standard drink per day for $\mathrm{BC}$ survivors, which may place them at increased risk of $\mathrm{BC}$ recurrence [18]. This reveals a gap between a perceived healthy diet and difficulty managing weight, with the need for additional support for women after BC diagnosis.

A small number of women had been advised to avoid red meat and dairy by their healthcare providers. A meta-analysis of 22 prospective cohort and five case control studies found that high and modest dairy consumption significantly reduced the risk of breast cancer compared with low dairy consumption [19]. In particular, yogurt and low-fat dairy reduced the risk of breast cancer while other dairy product types did not. As for red meat, a meta-analysis of 18 studies (a mix of cohort, nested case-control and randomised controlled trials) reported a $6 \%$ increase in $\mathrm{BC}$ risk (pooled RR 1.06) when comparing the highest to lowest category of unprocessed red meat consumptions, with a higher increased risk for processed red meat consumption of $9 \%$ [20]. This suggests that dietary advice for women with $\mathrm{BC}$ needs to be strengthened in order to reflect the current best available evidence.

Physical activity (PA) has multiple benefits on improving physical function, psychological distress, fatigue and quality of life, and may reduce co-morbidity and risk of other cancers as well as possibly improve cancer-specific and all-cause mortality [21]. As per the recent Clinical Oncology Society of Australia position statement on exercise in cancer care, which reflects guidelines produced internationally, people with cancer should be referred to accredited exercise physiologists to assist with progression towards PA goals. However, a significant proportion (38\%) of women in our study reported that they were less active than they were before diagnosis, with $41 \%$ of women reporting none or low levels of PA, highlighting 


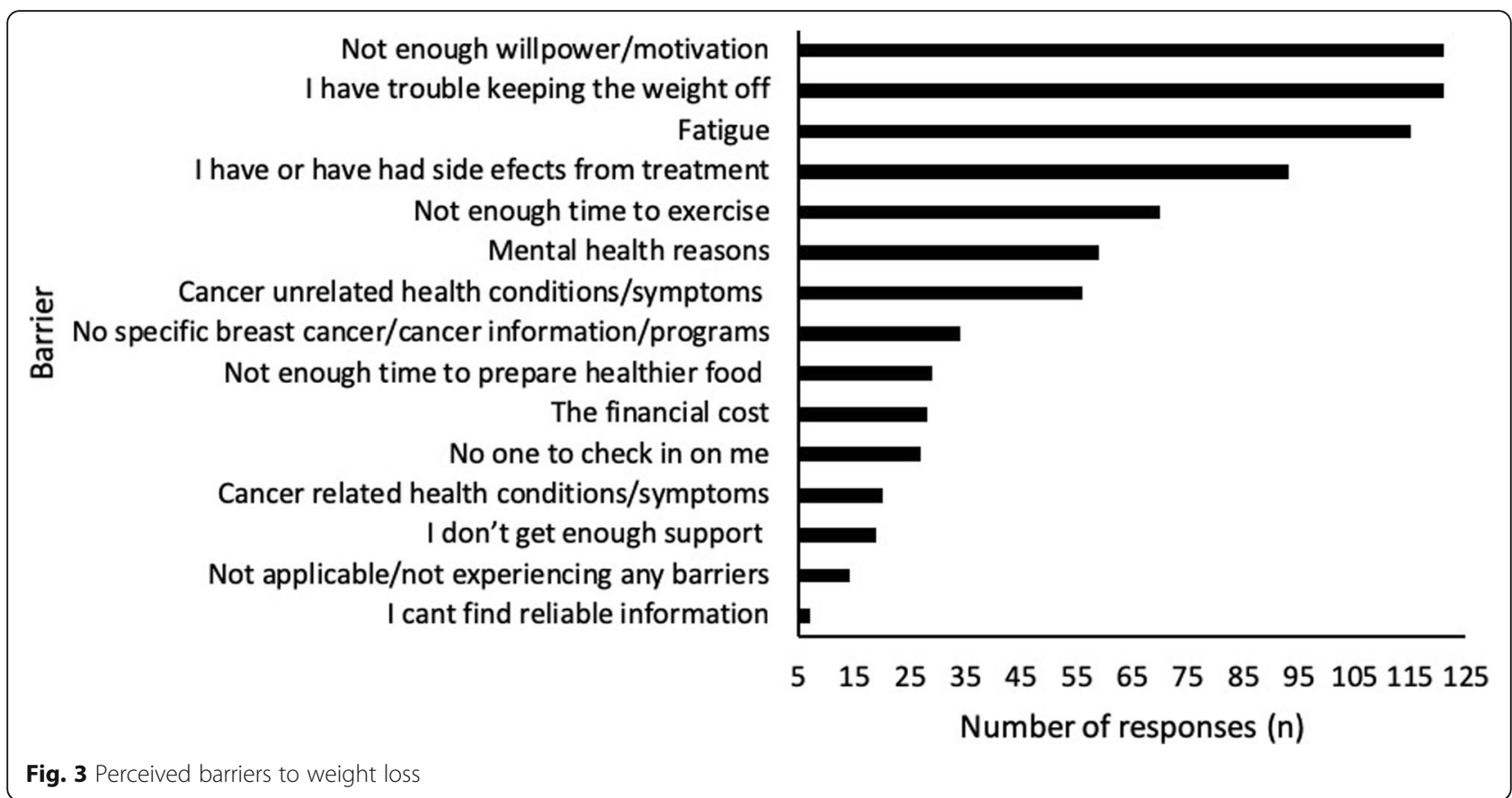

a gap in meeting the needs of women to achieve adequate PA levels.

Studies have reported that common barriers to health behaviors among BC survivors include higher-level barriers such as not having anyone to exercise with, low social support, and having responsibilities at home, along with individual-level barriers such as lack of willpower and fatigue [22]. Other studies have reported lack of support from family and conflicting advice from health professionals as barriers to healthy eating [10]. Cho et al. conducted a multilevel analysis of barriers to healthy behaviors amongst $97 \mathrm{BC}$ survivors, and reported that most

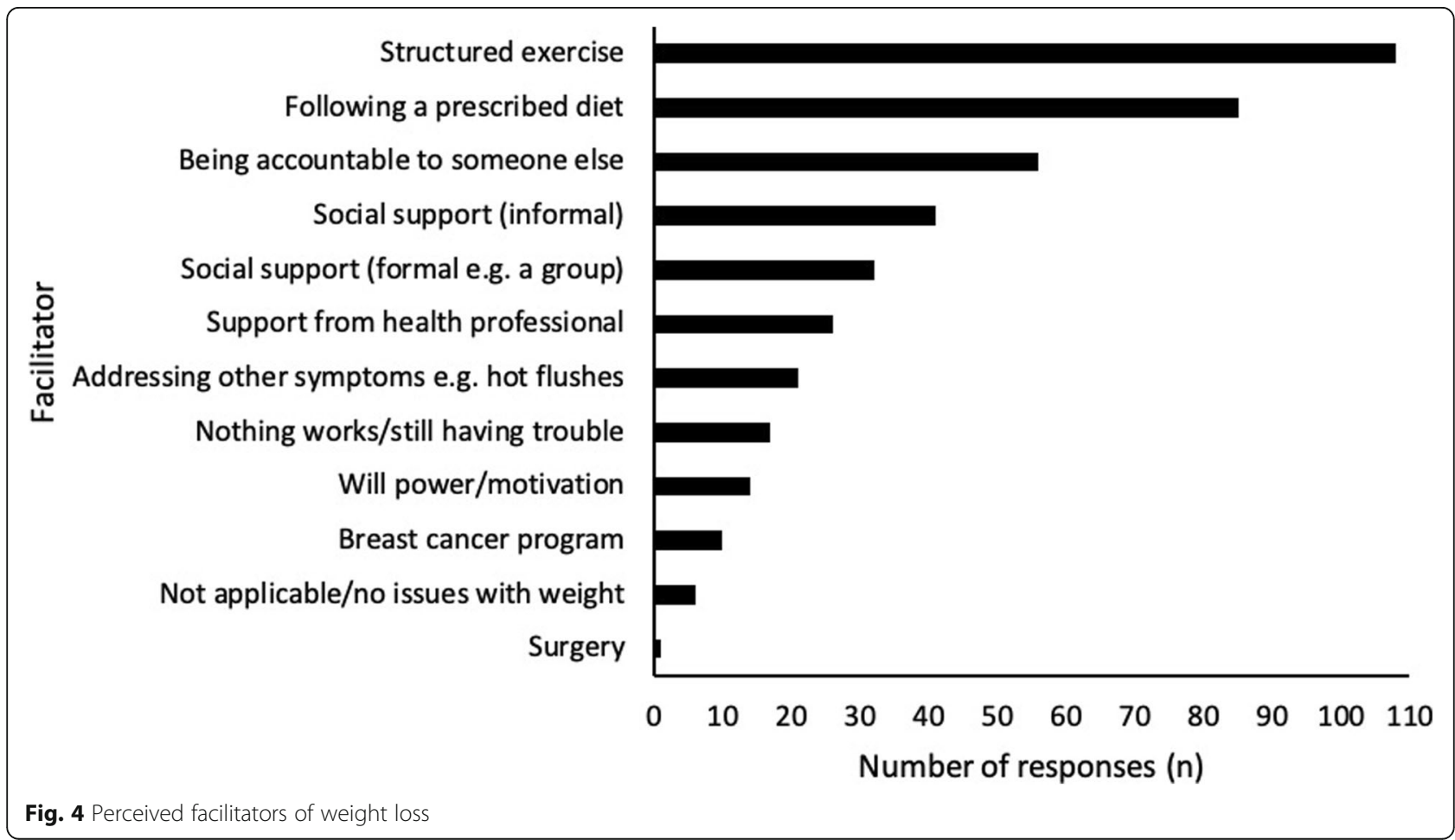


participants cited at least one barrier at the individual level - commonly, physical injury or symptoms (including fatigue), lack of time, and lack of motivation. Family and social obligations were also cited as barriers although less often. One quarter of participants reported at least one barrier at the organizational/environmental level (e.g. a busy job) [22]. These studies are consistent with the cited barriers in our study, of which a lack of willpower/motivation was the most cited, closely followed by difficulty keeping weight off, fatigue, and side effects from treatment. Not surprisingly, women who cited fatigue as a barrier were more likely to report low levels of PA. This is consistent with previous research suggesting that fatigue [23] is a common barrier to PA in young BC survivors. Fatigue is a common symptom in cancer survivors [24], and indeed PA is an effective treatment for post-cancer fatigue especially if supervised $[25,26]$. BC survivors who are experiencing fatigue should have access to a holistic and comprehensive approach to management of fatigue including PA supervised by an exercise physiologist, cognitive and behavioural strategies, and mindfulness and yoga-based interventions which show promise in alleviating post-BC fatigue [27, 28]. Our findings also suggest a gap in translation of the evidence on exercise as a treatment for post-cancer fatigue with women who cited fatigue as a barrier to PA possibly not being referred to exercise physiologists, which might be derived from their lower self-reported PA levels. Additionally, only $4 \%$ of women thought that a breast-cancer specific program would be helpful. This may be because perceived health stigma is common among people with breast cancer and is associated with negative emotions and reduced health-seeking behaviours [29], and our survey respondents may prefer to avoid being labelled a breast cancer survivor [30].

The most commonly cited facilitator of weight loss was a structured exercise regimen. Other facilitators included following a prescribed diet, being accountable to someone else and informal social support. These correlate well with the research priorities of PA, weight maintenance, diet, and social support programs identified by our respondents. Similar priorities have been identified by breast cancer researchers who acknowledge the difficulty in establishing large prospective randomised trials of physical and dietary interventions after breast cancer [31]. These findings were similar to a study of $14 \mathrm{BC}$ survivors who identified facilitators of weight management as family support, accountability to a coach, habitual PA and dietary changes such as reducing energy intake, increasing vegetable intake and portion control [10]. Overall, only diet and exercise were perceived to be effective for weight loss. The literature supports the effectiveness of this combined approach of diet, PA and behaviour modification. A systematic review on weight loss interventions in women with $\mathrm{BC}$ found that most of the interventions addressing a combination of diet, PA and behavior modification (5/8) achieved mean withingroup weight losses of $5 \%$ or more from baseline, and was associated with $30-40 \%$ reductions in insulin and leptin in women after BC treatment [32]. Interventions that treated diet and PA separately and focused less on behavior modification achieved less weight loss [32]. Interventions that used behaviour change techniques such as goal setting and action planning were more effective than those that did not, according to a review of 27 studies [33]. Previous research suggests a $25-50 \%$ [34] relative improvement in outcomes from lifestyle changes, however this data is largely from observational studies or poorly designed randomized trials which could reflect bias and/or confounding [35]. Behavioural modification would also be beneficial for the most commonly cited barrier in our survey, "not having enough willpower/motivation".

We achieved a higher than usual response rate (15\%) from the BCNA Survey and Review Group, where the typical response rate is $10 \%$ (email communication, Research and Evaluation Manager, BCNA 3 Oct 2017). We also obtained responses across Australia, with the proportion of respondents from each Australian State and Territory being similar to national averages on breast cancer incidence sourced from the Australian Institute of Health and Welfare cancer data [36].

There are some limitations to this study. First, although we achieved a $50 \%$ higher response rate from the BCNA Review and Survey Group than what is typically seen, the validity of our findings may be limited by the fact that the Review and Survey Group represents only a small proportion of all BCNA members. Furthermore, all data was self-reported, including diet and PA levels. Self-reported PA levels have low-moderate correlation with direct measurement [37] and memory-based dietary measures, even when more robust than our simple question about fruit and vegetable intake, are considered inaccurate when compared to direct quantification [38]. We did not capture sedentary behaviour nor measures of body composition such as percentage of fat-free mass. However, self-reported surveys allow for ease of data collection, and in this case facilitated a nation-wide survey. Further analysis of factors that predicted selfreported weight gain in our sample will be conducted.

\section{Conclusion}

Women in our study reported gaps in information provision and service provision in terms of weight gain prevention after $\mathrm{BC}$, which is a crucial part of improving outcomes after BC. More research is required on the effectiveness of diet and exercise interventions in $\mathrm{BC}$ survivors, particularly with regard to weight gain 
prevention. Successful weight gain prevention or weight loss programs should incorporate structured PA and dietary changes in combination with behavioural change and social support, and address perceived barriers to weight loss such as symptoms from breast cancer treatment and fatigue.

\section{Supplementary information}

Supplementary information accompanies this paper at https://doi.org/10. 1186/s12905-020-01002-9.

\section{Additional file 1.}

\section{Abbreviations}

BC: Breast Cancer; BCNA: Breast Cancer Network Australia; BMI: Body Mass Index; DCIS: Ductal Carcinoma In Situ; PA: Physical activity; WEL-SF: Weight Efficacy Lifestyle Scale (Short Form)

\section{Acknowledgements \\ We thank the consumer representatives from Breast Cancer Network Australia who provided feedback on the survey instrument used in this study; Natalie Zakhary who assisted with formatting the online survey; Kellie Stalgis-Bilinski who provided early feedback on the survey; and Karen Monaghan who assisted with data cleaning. Participants in this research were recruited from Breast Cancer Network Australia's (BCNA) Review and Survey Group, a national, online group of Australian women living with breast cancer who are interested in receiving invitations to participate in research. We acknowledge the contribution of the women involved in the Review and Survey Group who participated in this project.}

\section{Authors' contributions}

CE conceived of the study, designed the survey instrument, and collected the data. JB and $\mathrm{KB}$ contributed to design of the survey instrument and study. AEC led the data analysis. All authors contributed significantly to the interpretation of the data, drafting the manuscript, critical revision of the manuscript for important intellectual content, and provided final approval for publication.

\section{Funding}

This study did not receive any funding. CE is supported by an endowment from the Jacka Foundation of Natural Therapies.

\section{Availability of data and materials}

The datasets used and/or analysed during the current study are available from the corresponding author on reasonable request.

\section{Ethics approval and consent to participate}

All participants were provided with the Participant Information Sheet prior to commencing the survey, and consent was implied upon commencing the online anonymous survey. All procedures performed in studies involving human participants were in accordance with the ethical standards of the institutional and/or national research committee (Western Sydney University Human Research Ethics Committee, H12444, Oct 2017) and with the 1964 Helsinki declaration and its later amendments or comparable ethical standards.

\section{Consent for publication}

Not applicable.

\section{Competing interests}

As a medical research institute, NICM Health Research Institute receives research grants and donations from foundations, universities, government agencies, and industry. Sponsors and donors provide untied and tied funding for work to advance the vision and mission of the Institute. The authors declare that they have no competing interests.

\section{Author details}

'NICM Health Research Institute, Western Sydney University, Locked Bag 1797, Penrith, NSW, Australia. ${ }^{2}$ ICON Cancer Centre, Sydney Adventist Hospital, Wahroonga, NSW 2076, Australia.

Received: 30 December 2019 Accepted: 26 June 2020

Published online: 06 July 2020

\section{References}

1. Cancer compendium: information and trends by cancer type [https:// www.aihw.gov.au/reports/cancer/cancer-compendium-information-trendsby-cancer/report-contents/breast-cancer].

2. Bray FFJ, Soerjomataram I, Siegel RL, Torre LA, Jemal A. Global Cancer Statistics 2018: GLOBOCAN estimates of incidence ad mortality worldwide for 36 cancers in 185 countries. CA Cancer J Clin. in press.

3. Vance V, Mourtzakis M, McCargar L, Hanning R. Weight gain in breast cancer survivors: prevalence, pattern and health consequences. Obesity Rev. 2011;12(4):282-94.

4. Neuhouser ML, Aragaki AK, Prentice RL, Manson JE, Chlebowski R, Carty CL, Ochs-Balcom HM, Thomson CA, Caan BJ, Tinker LF, et al. Overweight, obesity, and postmenopausal invasive breast Cancer risk: a secondary analysis of the Women's Health Initiative randomized clinical trials. JAMA oncology. 2015;1(5):611-21.

5. Chan DS, Vieira AR, Aune D, Bandera EV, Greenwood DC, McTiernan A. Body mass index and survival in women with breast cancer-systematic literature review and meta-analysis of 82 follow-up studies. Ann Oncol. 2014;25.

6. Playdon MC, Bracken MB, Sanft TB, Ligibel JA, Harrigan M, Irwin ML. Weight Gain After Breast Cancer Diagnosis and All-Cause Mortality: Systematic Review and Meta-Analysis. J Natl Cancer Inst. 2015;107(12):djv275.

7. Siegel RL, Miller KD, Jemal A. Cancer statistics, 2018. CA Cancer J Clin. 2018; 68(1):7-30.

8. Vagenas D, DiSipio T, Battistutta D, Demark-Wahnefried W, Rye S, Bashford J, Pyke C, Saunders C, Hayes SC. Weight and weight change following breast cancer: evidence from a prospective, population-based, breast cancer cohort study. BMC Cancer. 2015:15:28

9. Ee C, Cave AE, Naidoo D, Bilinski K, Boyages J. Weight before and after a diagnosis of breast cancer or ductal carcinoma in situ: a national Australian survey. BMC Cancer. 2020;20(1):113.

10. Terranova CO, Lawler SP, Spathonis K, Eakin EG, Reeves MM. Breast cancer survivors' experience of making weight, dietary and physical activity changes during participation in a weight loss intervention. Support Care Cancer. 2017;25(5):1455-63.

11. Qualtrics. Qualtrics. Provo; 2018.

12. Ames GE, Heckman MG, Diehl NN, Grothe KB, Clark MM. Further statistical and clinical validity for the weight efficacy lifestyle questionnaire-short form. Eat Behav. 2015;18:115-9.

13. Russell A. Data Technical Report of the ALSWH: Derived variables not included in datasets; 2006

14. StataCorp. Stata Statistical Software Series 13: Release 13. 13th ed. College Station: StataCorp LP; 2013.

15. Daley AJ, Bowden SJ, Rea DW, Billingham L, Carmicheal AR. What advice are oncologists and surgeons in the United Kingdom giving to breast cancer patients about physical activity? Int J Behav Nutr Phys Act. 2008;5:46.

16. Jones LWCK, Peddle C, Mackey JR. Oncologists' opinions towards recommending exercise to patients with cancer: a Canadian national survey. Support Care Cancer. 2005;13(11):929-37.

17. Dimitrios A, Koutoukidis SL, Fisher A, Williams K, Croker H, Beeken RJ. Lifestyle advice to cancer survivors: a qualitative study on the perspectives of health professionals. BMJ Open. 2018;8:3

18. Runowicz CD, Leach CR, Henry NL, Henry KS, Mackey HT, Cowens-Alvarado RL, Cannady RS, Pratt-Chapman ML, Edge SB, Jacobs LA, et al. American Cancer Society/American Society of Clinical Oncology breast Cancer survivorship care guideline. Ca-a Cancer J Clin. 2016;66(1):44-73.

19. Zang J, Shen M, Du S, Chen T, Zou S. The association between dairy intake and breast Cancer in Western and Asian populations: a systematic review and meta-analysis. J Breast Cancer. 2015;18(4):313-22.

20. Farvid MS, Stern MC, Norat T, Sasazuki S, Vineis P, Weijenberg MP, Wolk A Wu K, Stewart BW, Cho E. Consumption of red and processed meat and breast cancer incidence: a systematic review and meta-analysis of prospective studies. Int J Cancer. 2018;143(11):2787-99. 
21. Clinical Oncology Society of Australia. COSA Position Statement on Exercise in Cancer Care. Sydney; 2018.

22. Cho $\mathrm{D}$, Park $\mathrm{CL}$. Barriers to physical activity and healthy diet among breast cancer survivors: A multilevel perspective. Eur J Cancer Care. 2018;27(1). https://doi.org/10.1111/ecc.12772.

23. Ventura EE, Ganz PA, Bower JE, Abascal L, Petersen L, Stanton AL, Crespi CM. Barriers to physical activity and healthy eating in young breast cancer survivors: modifiable risk factors and associations with body mass index. Breast Cancer Res Treat. 2013;142(2):423-33.

24. Servaes $P$, Verhagen $C$, Bleijenberg $G$. Fatigue in cancer patients during and after treatment: prevalence, correlates and interventions. Eur J Cancer (Oxford, England : 1990). 2002;38(1):27-43.

25. Juvet LK, Thune I, Elvsaas IKO, Fors EA, Lundgren S, Bertheussen G, Leivseth G, Oldervoll LM. The effect of exercise on fatigue and physical functioning in breast cancer patients during and after treatment and at 6 months follow-up: A meta-analysis. Breast (Edinburgh, Scotland). 2017;33:166-77.

26. Meneses-Echavez JF, Gonzalez-Jimenez E, Ramirez-Velez R. Effects of supervised exercise on cancer-related fatigue in breast cancer survivors: a systematic review and meta-analysis. BMC Cancer. 2015;15:77.

27. El-Hashimi D, Gorey KM. Yoga-Specific Enhancement of Quality of Life Among Women With Breast Cancer: Systematic Review and Exploratory Meta-Analysis of Randomized Controlled Trials. J Evidence-Based Integr Med. 2019;24:2515690x19828325.

28. Haller H, Winkler MM, Klose P, Dobos G, Kummel S, Cramer H. Mindfulnessbased interventions for women with breast cancer: an updated systematic review and meta-analysis. Acta Oncol. 2017;56(12):1665-76

29. Wang Q-X, Bai Y, Lu G-F, Zhang C-Y. Perceived health-related stigma among patients with breast cancer. Chin Nurs Res. 2017:4(4):158-61.

30. Khan NF, Harrison S, Rose PW, Ward A, Evans J. Interpretation and acceptance of the term 'cancer survivor': a United Kingdom-based qualitative study. Eur J Cancer Care. 2012;21(2):177-86.

31. Eccles SA, Aboagye EO, Ali S, Anderson AS, Armes J, Berditchevski F, Blaydes JP, Brennan K, Brown NJ, Bryant HE, et al. Critical research gaps and translational priorities for the successful prevention and treatment of breast cancer. Breast Cancer Res. 2013;15(5):R92.

32. Reeves MM, Terranova CO, Eakin EG, Demark-Wahnefried W. Weight loss intervention trials in women with breastcancer: a systematic review. Obes Rev. 2014;15:749-68.

33. Hoedjes M, van Stralen MM, Joe STA, Rookus M, van Leeuwen F, Michie S, Seidell JC, Kampman E. Toward the optimal strategy for sustained weight loss in overweight cancer survivors: a systematic review of the literature. J Cancer Surviv. 2017;11(3):360-85.

34. Protani $\mathrm{M}$, Coory $\mathrm{M}, \mathrm{Martin} \mathrm{JH}$. Effect of obesity on survival of women with breast cancer: systematic review and meta-analysis. Breast Cancer Res Treat. 2010;123(3):627-35.

35. Ganz PA: Improving Outcomes for Breast Cancer Survivors: Perpectives on Research Challenges and Opportunities ProQuest Ebook Central, https:// ebookcentral.proquest.com/lib/uwsau/detailaction?doclD=2096718: 2015.

36. Australian Institute of Health and Welfare. Cancer Data in Australia. Canberra; 2018.

37. Prince SA, Adamo KB, Hamel ME, Hardt J, Gorber SC, Tremblay M. A comparison of direct versus self-report measures for assessing physical activity in adults: a systematic review. Int J Behav Nutr Phys Act. 2008;5(1):56.

38. Archer E, Lavie CJ, Hill JO. The Failure to Measure Dietary Intake Engendered a Fictional Discourse on Diet-Disease Relations. Front Nutr. 2018:5:105.

\section{Publisher's Note}

Springer Nature remains neutral with regard to jurisdictional claims in published maps and institutional affiliations.

Ready to submit your research? Choose BMC and benefit from:

- fast, convenient online submission

- thorough peer review by experienced researchers in your field

- rapid publication on acceptance

- support for research data, including large and complex data types

- gold Open Access which fosters wider collaboration and increased citations

- maximum visibility for your research: over $100 \mathrm{M}$ website views per year

At $\mathrm{BMC}$, research is always in progress.

Learn more biomedcentral.com/submissions 